\title{
Sound attenuation and anharmonic damping in solids with correlated disorder
}

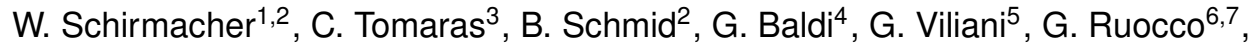 \\ T. Scopignd6]7 \\ ${ }^{1}$ Physik-Department E13, Technische Universität München, James-Franck-Strasse 1, \\ D-85747 Garching, Germany \\ 2 Fachbereich Physik, Universität Mainz, Germany \\ 3 Arnold Sommerfeld Center for Theoretical Physics, Ludwig-Maximilians-Universität München, \\ Theresienstr. 37, D-80333 München, Germany \\ ${ }^{4}$ ESRF Grenoble \\ 5 Dipt. di Fisica, Universitá di Trento, Italy \\ 6 Dipt. di Fisica, Universitá di Roma, Italy \\ 7 IPCF-CNR, Sezione di Roma, c/o Sapienza Universita' di Roma, Italy
}

Received April 3, 2010, in final form April 14, 2010

\begin{abstract}
We study via self-consistent Born approximation a model for sound waves in a disordered environment, in which the local fluctuations of the shear modulus $G$ are spatially correlated with a certain correlation length $\xi$. The theory predicts an enhancement of the density of states over Debye's $\omega^{2}$ law (boson peak) whose intensity increases for increasing correlation length, and whose frequency position is shifted downwards as $1 / \xi$. Moreover, the predicted disorder-induced sound attenuation coefficient $\Gamma(k)$ obeys a universal scaling law $\xi \Gamma(k)=f(k \xi)$ for a given variance of $G$. Finally, the inclusion of the lowest-order contribution to the anharmonic sound damping into the theory allows us to reconcile apparently contradictory recent experimental data in amorphous $\mathrm{SiO}_{2}$.
\end{abstract}

Key words: sound attenuation, vibrational properties of disordered solids, boson peak, anharmonic interactions

PACS: $63.50 .-x, 43.20 .+g, 65.60 .+a$

The vibrational properties of disordered solids at $\mathrm{THz}$ frequencies are subject of an enormous attention both from the experimental and from the theoretical side [1], due to the related anomalies observed in the specific heat and thermal conductivity of glasses [2]. The origin of an excess of the vibrational density of states (DOS) over the Debye prediction ("boson peak") at THz frequencies and its relation to the rather anomalous sound attenuation in the same frequency regime is in focus of a lively debate [3 $[5]$. In particular, the origin of the dispersion and attenuation of sound-like excitation in the $\mathrm{THz}$ frequency range has been a matter of controversy quite recently [6, 7]. In spite of this debate, nowadays many authors agree that the boson peak and the frequency dependence of the sound attenuation are the related phenomena dictated by the structural disorder, rather than by anharmonic interactions, and occur at frequencies at which the wavevector $k$ looses its significance for labeling the transverse vibrational states (Ioffe-Regel regime) [8].

The way the disorder controls the thermophysical properties, however, is still not fully understood, and the experimental phenomenology is not completely reproduced by the current fluctuating-elastic-constant (FE) approaches [6, 9, 10], which are based on zero-range correlations.

The FE approach has been recently applied to low-frequency Raman scattering and for the first time accounted for the experimentally observed frequency dependence, which is different from incoherent neutron scattering [11]. In this study and in a recent comparison of a scalar FE model with a simulation of a simple model having correlated disorder [12] it was realized that the finite 
correlation length $\xi$ of the elasticity fluctuations plays an important role discussing the vibrational anomalies. A similar conclusion was drawn from molecular-dynamics simulations of quenched Lennard-Jones Argon and $\mathrm{SiO}_{2}$ [13. In the latter study it emerged that these correlations exist over an extended number of inter-atomic distances. This verifies a conjecture of Elliott [14] quite a time ago.

In the present paper we use the full vector FE approach [10] to study the effect of a finite correlation length and the presence of anharmonic interactions. We find that the BP becomes strongly enhanced with increasing correlation length, a result which emphasizes the importance of this latter property in real systems. We further demonstrate that $\xi$ times the disorder-induced sound attenuation constant is a universal function of $\xi k$ (where $k$ is the wavenumber).

We consider an elastic continuum, in which the shear modulus $G$ fluctuates in space around its mean value $G_{0}$ (the bulk modulus $K_{o}$ is supposed to be constant): $G(\mathbf{r})=G_{0}+\Delta G(\mathbf{r})$, we also assume that the correlation function of $\Delta G(\mathbf{r}), C(\mathbf{r})=\left\langle\Delta G\left(\mathbf{r}+\mathbf{r}_{0}\right) \Delta G\left(\mathbf{r}_{0}\right)\right\rangle$ and its Fourier transform are of the forms

$$
\begin{aligned}
C(\mathbf{r}) & =\left\langle\Delta G^{2}\right\rangle \mathrm{e}^{-r / \xi}, \\
C(\mathbf{k}) & =\left\langle\Delta G^{2}\right\rangle(8 \pi / \xi)\left[k^{2}+\xi^{-2}\right]^{-2} .
\end{aligned}
$$

The corresponding mean-field equation for the low-wavenumber self energy $\Sigma(\omega)=\Sigma(q=0, \omega)$ (selfconsistent Born approximation, SCBA) takes the form [11, 12, 15, 16]

$$
\Sigma(\omega)=\frac{\gamma}{2 \varphi_{3}\left\langle\Delta G^{2}\right\rangle} \int_{|\mathbf{k}|<k_{\mathrm{D}}}\left(\frac{\mathrm{d} \mathbf{k}}{2 \pi}\right)^{3} C(k)\left[\chi_{L}(k, \omega)+\chi_{T}(k, \omega)\right]
$$

with

$$
\begin{aligned}
& \chi_{L}(k, \omega)=k^{2}\left[-\omega^{2}+k^{2}\left(v_{L, 0}^{2}-2 \Sigma(\omega)\right)\right]^{-1}, \\
& \chi_{T}(k, \omega)=k^{2}\left[-\omega^{2}+k^{2}\left(v_{T, 0}^{2}-\Sigma(\omega)\right)\right]^{-1} .
\end{aligned}
$$

Here $\gamma=\left\langle\Delta G^{2}\right\rangle \varphi_{3} / v_{0}^{4}$. is the "disorder parameter", $v_{L, 0}, v_{T, 0}$, are the (unrenormalized) sound velocities, and $\varphi_{3}=\int_{|\mathbf{k}|<k_{\mathrm{D}}}(\mathrm{d} \mathbf{k} / 2 \pi)^{3} C(\mathbf{k})$ is a normalization constant. $k_{\mathrm{D}}$ is the usual Debye-cutoff, typical values have been elaborated in [6].

The DOS, given by

$$
g(\omega)=\frac{2 \omega}{3 \pi} \int_{|\mathbf{k}|<k_{\mathrm{D}}}\left(\frac{\mathrm{d} \mathbf{k}}{2 \pi}\right)^{3} \frac{1}{k^{2}} \operatorname{Im}\left\{\chi_{L}(k, \omega)+2 \chi_{T}(k, \omega)\right\}
$$

is reported in figure 1. Here we have plotted the "reduced DOS" $g(\omega) / g_{\mathrm{D}}(\omega)$ (where $g_{\mathrm{D}}$ is Debye's DOS) for three values of $\gamma$ and five values of $\xi$. First we notice that, similarly to the uncorrelated case $(\xi \rightarrow 0)[6,9,10]$ there exists a critical amount of disorder $\gamma_{c}$, beyond which the system becomes unstable. The "boson peak" becomes more pronounced and is located at lower frequencies as this value is approached. However, at variance with the experimental data, the maximum amplitude of the boson peak predicted from the $\xi=0$ case is a factor larger than the Debye expectation. The interesting feature appearing in the correlated case $(\xi>0)$ is that the boson peak amplitude increases and its position shifts towards lower frequencies with increasing $\xi$. In figure 1 - where we have taken the frequencies scaled by $v_{T} / \xi$ in order to show that the boson peak frequencies scales as $1 / \xi$ - one can see that the boson peak amplitude can reach the value as high as ten with still reasonable $\xi$ value.

The sound attenuation constant (i.e., the width of the Brillouin line in $\left.\chi_{L}^{\prime \prime}(k, \omega)\right)$ is given in terms of the imaginary part of the self-energy $\Sigma^{\prime \prime}(\omega)$ as [6]

$$
\Gamma(k)=2 \frac{k}{v_{L}} \Sigma^{\prime \prime}\left(\omega=k / v_{L}\right),
$$




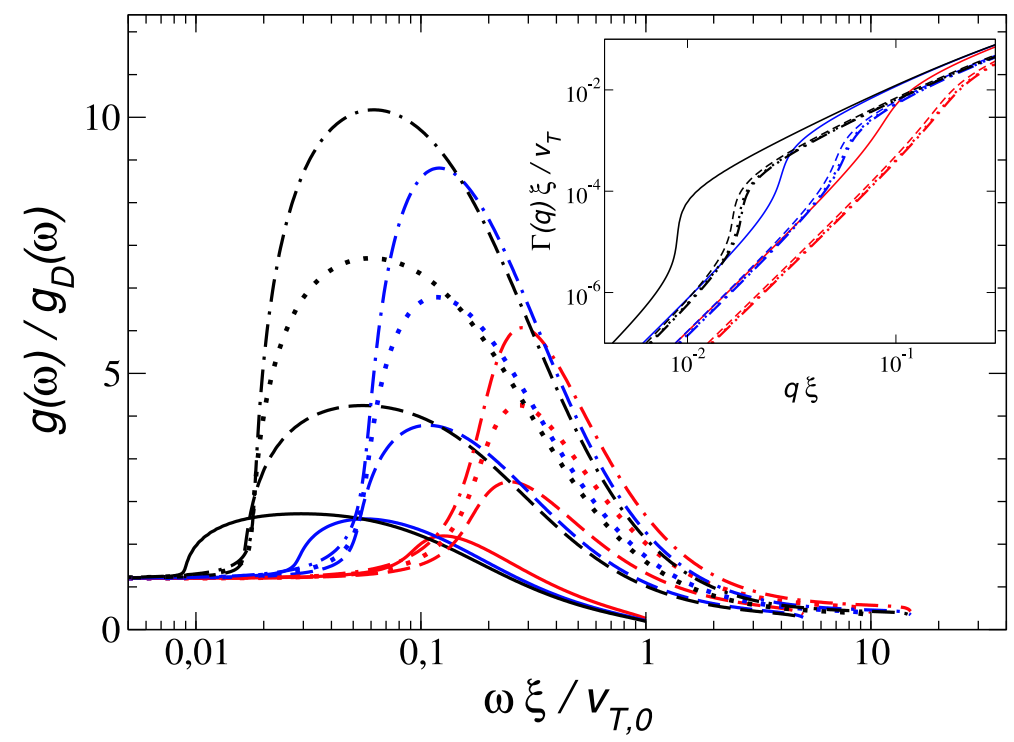

Figure 1. Reduced DOS $g(\omega) / g_{\mathrm{D}}(\omega)$ against scaled frequency $\omega \xi / v_{T, 0}$ for $\xi=1 / k_{\mathrm{D}}$ (full lines) $\xi=5 / k_{\mathrm{D}}$ (dashed lines), $\xi=10 / k_{\mathrm{D}}$ (dotted lines), $\xi=15 / k_{\mathrm{D}}$ (dash-dotted lines), for three disorder parameters (from left to right) $\gamma-\gamma_{\mathrm{c}}=0.0001$ (black), 0.001 (blue) and 0.01 (red). Inset: Scaled Brillouin linewidth $\Gamma \xi / v_{0}$ against scaled wavenumber $q \xi$ for the same parameters and with the same line and color codes.

where $v_{L}=\left[v_{L, 0}^{2}-2 \Sigma^{\prime}(\omega=0)\right]^{1 / 2}$ is the renormalized longitudinal sound velocity. In particular, the relation between $\Gamma$ and the excess DOS derived for $\xi=0$ (see equation (5) in [6]) - and this has been found to be in agreement with the experimental data [6] - remains the same also for $\xi>0$. If one now introduces the dimensionless variables $\tilde{\Sigma}=\Sigma / v_{T, 0}^{2}, \tilde{\omega}=\omega \xi / v_{T, 0}$ and $\tilde{k}=k \xi$ and inserts these into the SCBA equation (2) one realizes that the correlation length only appears via the upper cutoff $\tilde{k}_{\mathrm{D}}=k_{\mathrm{D}} \xi$. This means that for large enough $\xi$ (in which case the cutoff does not play any role) $\tilde{\Sigma}$ and $\tilde{\Gamma}$ does not depend on $\xi$. This implies, in turn, that $\tilde{\Gamma}=\Gamma \xi / v_{T, 0}$ is - for a fixed disorder parameter $\gamma$ - a universal function of $k . \tilde{\Sigma}$ (and, in fact $\Sigma$ as well) is - within our approach - a universal function of $\xi \omega / v_{L}$ or $\xi k$.

In the inset of figure 1 we have plotted $\tilde{\Gamma}$ against $\tilde{k}$ for $d=3$, for the three $\gamma$ values of figure 1 and for $\xi=1 / k_{\mathrm{D}}, 5 / k_{\mathrm{D}}, 10 / k_{\mathrm{D}}$, and $15 / k_{\mathrm{D}}$. We see that the scaling is obeyed except for $\xi=1 / k_{\mathrm{D}}$ as expected. The crossover from the Rayleigh regime $\tilde{\Gamma} \propto \tilde{k}^{4}$ to a behavior $\tilde{\Gamma} \propto \tilde{k}^{s}$ with $s \approx 2$, occurring at the low frequency edge of the boson peak [ 6 , 10], is now understood to be a universal feature independent of the magnitude of the correlation length (see figure 1).

In real amorphous solids, the relation $\Gamma(k) \propto k^{2}$ holds - at frequencies around the boson peak frequency - for almost all glasses. This is in agreement with the present theory, which predicts $\Gamma(k) \propto k^{2}$ in the boson peak for all values of $\gamma$ and $\xi$. On the contrary, a clear-cut Rayleigh scattering law $\left(\Gamma(k) \propto k^{4}\right)$ is seldomly observed. Generally, at much lower frequencies, one finds a sound attenuation proportional to $k^{2}$, which increases with temperature and is therefore attributed to anharmonic effects. Some evidence of a possible transition between $k^{2}$ and $k^{4}$ behavior has been found for vitreous silica [17].

In order to account for this contribution we consider a cubic anharmonic interaction of the form 19

$$
\mathcal{V}_{\mathrm{an}}=\lambda_{0} \sum_{i j} u_{i i} v_{i j} v_{i j}+G(\mathbf{x})\left(\sum_{i j \ell} u_{i j} v_{i \ell} v_{\ell j}+g_{1} \sum_{i} u_{i i}^{3}\right)
$$

with the linearized strain- $u_{i j}=\frac{1}{2}\left(\partial_{j} u_{i}+\partial_{i} u_{j}\right)$ and rotation $v_{i j}=\frac{1}{2}\left(\partial_{j} u_{i}-\partial_{i} u_{j}\right)$ tensor and $g_{1}$ a phenomenological mode-Grüneisen-like parameter. Using a replica field formalism at finite temperature $T$, a set of mode-coupling-like self consistency equations for the full dynamical sus- 
ceptibilities has been derived [20]. This treatment involving an Akhiezer-like 'mode-coupling' parameter $g\left(\left\langle\Delta G^{2}\right\rangle, \xi, k_{\mathrm{B}} T\right)=\left(1+g_{1}^{2}\right)\left\langle\Delta G^{2}\right\rangle k_{\mathrm{B}} T / 3 \xi^{3} \pi^{4} \rho^{3} \bar{v}_{T}^{4}$. In a perturbative regime, the relevant anharmonic contribution to the attenuation of density fluctuations can be reduced to

$$
\Sigma_{\mathrm{an}, \mathrm{i}}^{\prime \prime}(0, \tilde{\omega})=g \int_{0}^{\infty} \int_{0}^{\xi k_{\mathrm{D}}} \mathrm{d} \tilde{k} \tilde{k}^{2} \int_{0}^{\xi k_{\mathrm{D}}} \mathrm{d} \tilde{q} \tilde{q}^{2} \frac{\mathrm{d} \tilde{\tilde{\omega}}}{\overline{\tilde{\chi}}} \tilde{\chi}_{T}^{\prime \prime}\left(\tilde{\mathbf{q}}, \tilde{\bar{\omega}}_{+}\right)\left[\tilde{\chi}_{T}^{\prime \prime}(\tilde{\mathbf{k}}, \tilde{\bar{\omega}}+\tilde{\omega})-\tilde{\chi}_{T}^{\prime \prime}(\tilde{\mathbf{k}}, \tilde{\bar{\omega}}-\tilde{\omega})\right]
$$

where the full susceptibilities are replaced with their harmonic disorder-modified counterparts (2). The specific form of the correlation function enters the anharmonic sound attenuation function only indirectly through the harmonic susceptibilities. The latter ones, are only weakly effected by a change from exponential to Gaussian correlations. At room temperature, the integral (7) scales like $T \omega$ for $\omega \ll \omega_{\mathrm{B}}$. This is already suggested by the specific form of the integral kernel, and has been confirmed numerically [20].

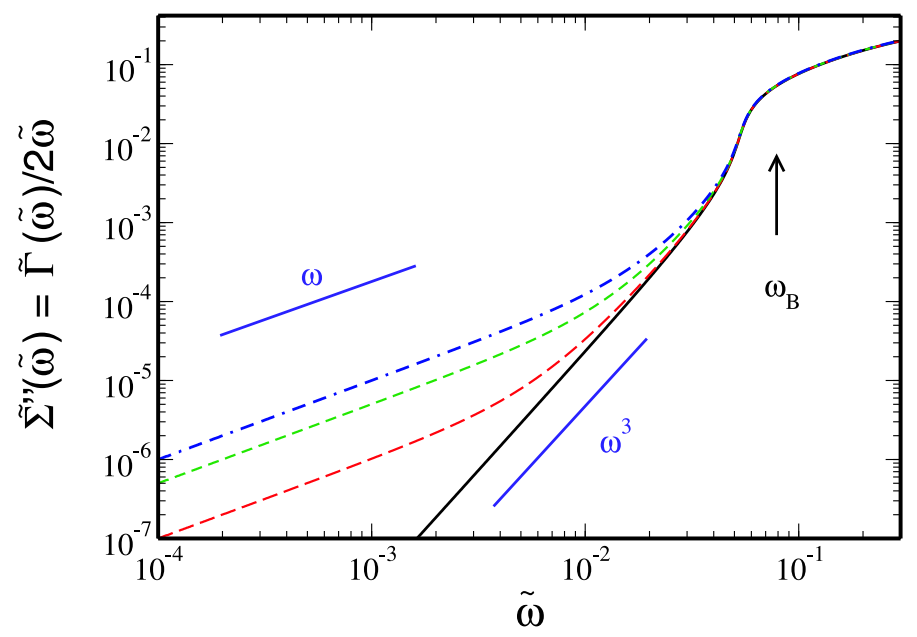

Figure 2. Brillouin linewidth, divided by frequency $\tilde{\Sigma}^{\prime \prime} \cdot \alpha$ including disorder and anharmonicity for $\xi=2 / k_{\mathrm{D}}, \gamma / \gamma_{\mathrm{c}}=0.99, \alpha=\left(v_{L} / v_{T}\right)^{2}=2.52$ for different temperatures $T / T_{0}=0$ (full,black), 0.001 (long dashes, red), 0.005 (short dashes, green), 0.01 (dash-dots, blue). $T_{0}$ is defined by $\tilde{\Sigma}_{\text {an }}^{\prime \prime}(\tilde{\omega})=\left(T / T_{0}\right) \tilde{\omega}$ in the linear region.

Figure 2 shows the full Brillouin linewidth due to disorder and anharmonicity with the known parameters of $\mathrm{SiO}_{2}[6] \gamma=0.99, \Delta G_{\mathrm{c}}^{2}=0.401, \rho^{2} v_{T}^{4}, \xi=2 / k_{\mathrm{D}},\left(v_{L} / v_{T}\right)^{2}=2.52, k_{\mathrm{D}}=1.6 \times 10^{10} / \mathrm{m}$, $T=300 \mathrm{~K}, g_{1} \approx 0$. The anharmonic corrections already lead to deviations from the disordered contribution slightly below the shoulder of the BP, the highest frequency, where the Akhiezer-like behavior is present in $\mathrm{SiO}_{2}$, is therefore predicted to be one order of magnitude below the BP, i.e., in the $100 \mathrm{GHz}$ regime.

This compares qualitatively with some recent inelastic UV light scattering data of vitreous $\mathrm{SiO}_{2}$ by Masciovecchio et al. [17]. They observed the crossover from a $\omega^{2}$ to a very steep increase - compatible with a $\omega^{4}$ law - around $100 \mathrm{GHz}$.

More recently Devos et al. [18] reported on the results of the measurements of sound absorption on thin films of $\mathrm{SiO}_{2}$ produced by chemical vapor deposition (CVD). These $\Gamma(k)$ data are found to be different from the data of [17]. The authors of [18], implicitly assuming that the structure of the materials investigated in the two sets of experiments are the same, claim that the data sets reported in [17] must be in error.

As it is well known, the structure of disordered solids crucially depends on the preparation method [21]. A glass, which is quenched from the melt, is known to have a much more relaxed structure than an amorphous material evaporated onto a cold substrate from the gaseous phase. Therefore, we believe that both the anharmonic coupling strength as well as the correlation length of differently prepared materials can differ considerably. This may be the reason that the AkhiezerRayleigh-crossover might occur at different frequencies in differently prepared materials. 
In conclusion, we have combined a model in which the shear modulus exhibits spatially correlated fluctuations with an anharmonic interaction. By this we are able to discuss these phenomena in terms of the structure of the materials and to solve an apparent contradiction recently reported in the literature. More importantly, we have at hand a theory capable of quantitatively reproducing most of the phenomena related to the high frequency vibrations in glasses, such as the existence of a boson peak and the puzzling $k$ dependent behavior of the sound attenuation.

\section{References}

1. Binder K., Kob W., Glassy Materials and Disordered Solids. World Scientific, Singapore, 2005.

2. Ruocco G., Nature Mater., 2008, 7, 842.

3. Horbach J., Kob W., Binder K., Eur. Phys. J. B, 2001, 19, 531.

4. Nakayama T., Rep. Prog. Phys., 2002, 65, 1195.

5. Gurevich V.L., Parshin D.A., Schober H.R., Phys. Rev. B, 2003, 67, 094203.

6. Schirmacher W., Ruocco G., Scorpigno T., Phys. Rev. Lett., 2007, 98, No. 2, 025501.

7. Rufflé B., Parshin D.A., Courtens E., Vacher R., Phys. Rev. Lett., 2008, 100, No. 1, 015501.

8. Shintani H., Tanaka H., Nature Mater., 2008, 7, 7, 670.

9. Maurer E., Schirmacher W., J. Low-Temp. Phys., 2004, 137, 453.

10. Schirmacher W., Europhys. Lett., 2006, 73, 892.

11. Schmid B., Schirmacher W., Phys. Rev. Lett., 2008, 100, 137402.

12. Schirmacher W., Schmid B., Tomaras C., Viliani G., Baldi G., Ruocco G., Scorpigno T., Phys. Stat. Sol. (c), 2008, 5, 862 .

13. Leonforte F., Tanguy A., Wittmer J.P., Barrat J.-L., Phys. Rev. Lett., 2006, 97055501.

14. Elliott S.R., Europhys. Lett., 1991, 19, 201.

15. John S., Stephen M.J., Phys. Rev. B, 1983, 28, 6358.

16. Ignatchenko V.A., Felk V.A., Phys. Rev. B, 2006, 74, 174415.

17. Masciovecchio C., Baldi G., Caponi S., Comez L., Di Fonzo S., Fioretto D., Fontana A., Gessini A., Santucci S.C., Sette F., Viliani G., Vilmercati P., Ruocco G., Phys. Rev. Lett., 2006, 97, 035501.

18. Devos A., Foret M., Ayrinhac S., Emery P., Rufflé B., Phys. Rev. B, 2008, 77, 100201.

19. Landau L.D., Lifshitz E.M., Theory of Elasticity. Butterworth, Oxford, 1986.

20. Tomaras C., Schmid B., Schirmacher W., Phys. Rev. B, 2010, 81, 104206.

21. Elliott S.R., Physics of Amorphous Materials, 2nd edition. Longman Scientific, London, 1990. 


\title{
Послаблення звуку та ангармонічне загасання у твердих тілах зі скорельованим безладом
}

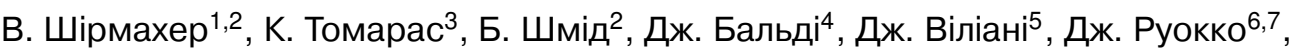

Т. Скопіньйб617

1 Відділення фізики Е13, Технічний університет Мюнхена, Ґархінґ, Німеччина

2 Факультет фізики, Університет Майнца, Майнц, Німеччина

3 Центр теоретичної фізики Арнольда Зоммерфельда, Мюнхенський університет ім. Людвіґа-Максиміліана, Мюнхен, Німеччина

4 ЄЦСР, Ґренобль, Франція

5 Факультет фізики, Університет Тренто, Тренто, Італія

6 Факультет фізики, Римський університет, Рим, Італія

7 Центр SOFT-INFM-CNR, Italy

За допомогою самоузгодженого наближення Борна ми досліджуємо модель для звукових хвиль у невпорядкованому оточенні, де локальні флуктуації модуля зсуву $G \in$ просторово скорельовані $з$ певною кореляційною довжиною $\xi$. Теорія передбачає зростання густини станів понад законом Дебая $\omega^{2}$ (бозонний пік), чия інтенсивність зростає із збільшенням кореляційної довжини та частота зсувається в область низьких частот як $1 / \xi$. Крім того, передбачено, що коефіцієнт викликаного безладом послаблення звуку $\Gamma(k)$ задовільняє універсальному закону скейлінґу $\xi \Gamma(k)=f(k \xi)$ для заданої варіації $G$. Врешті, врахування внеску найнижчого порядку до ангармонічного загасання звуку в теорії дозволяє нам узгодити наявні суперечливі недавні експериментальні дані для аморфного $\mathrm{SiO}_{2}$.

Ключові слова: послаблення звуку, вібраційні властивості невпрорядкованих твердих тіл, бозонний пік, ангармонічні взаємодії 